Research Article

\title{
Association of c.56C > G (rs3135506) Apolipoprotein A5 Gene Polymorphism with Coronary Artery Disease in Moroccan Subjects: A Case-Control Study and an Updated Meta-Analysis
}

\author{
Imane Morjane $\mathbb{D}^{1,2}$ Hicham Charoute, ${ }^{1}$ Sanaa Ouatou, ${ }^{1}$ Lamiae Elkhattabi, ${ }^{1,2}$ \\ Houda Benrahma, ${ }^{1,3}$ Rachid Saile $\mathbb{D}^{2},{ }^{2}$ Hassan Rouba, ${ }^{1}$ and Abdelhamid Barakat $\left(\mathbb{D}^{1}\right.$ \\ ${ }^{1}$ Laboratory of Genomics and Human Genetics, Institut Pasteur Du Maroc, Casablanca, Morocco \\ ${ }^{2}$ Laboratory of Biology and Health, Faculty of Sciences Ben M'Sik, Hassan II University of Casablanca, Casablanca, Morocco \\ ${ }^{3}$ National Reference Laboratory (LNR), Faculty of Medicine, Mohammed VI University of Health Sciences (UM6SS), \\ Casablanca, Morocco
}

Correspondence should be addressed to Abdelhamid Barakat; hamid.barakat@pasteur.ma

Received 25 June 2019; Revised 29 February 2020; Accepted 3 March 2020; Published 4 August 2020

Academic Editor: Robert Chen

Copyright (c) 2020 Imane Morjane et al. This is an open access article distributed under the Creative Commons Attribution License, which permits unrestricted use, distribution, and reproduction in any medium, provided the original work is properly cited.

\begin{abstract}
Purpose. Coronary artery diseases (CAD) are clinical cardiovascular events associated with dyslipidemia in common. The interaction between environmental and genetic factors can be responsible for CAD. The present paper aimed to examine the association between c.56C > G (rs3135506) APOA5 gene polymorphism and CAD in Moroccan individuals and to perform an association update meta-analysis. Materials and Methods. The c.56C > G variant was genotyped in 122 patients with CAD and 134 unrelated controls. Genetic association analysis and comparison of biochemical parameters were performed using $R$ statistical language. In addition, a comprehensive meta-analysis including eleven published studies in addition to our case-control study results was conducted using Review Manager 5.3. Publication bias was examined by Egger's test and funnel plot. Results. The casecontrol study data showed that the c.56C $>\mathrm{G}$ polymorphism was associated with CAD susceptibility under codominant $(P$-value $=0.001)$, recessive $(P$-value $<0.001)$ and log-additive $(P$-value $=0.008)$ inheritance models. In addition, this polymorphism was significantly associated with increased levels of systolic and diastolic blood pressures, triglycerides, glycemia, and total cholesterol. Furthermore, meta-analysis showed a significant association between the c.56C $>\mathrm{G}$ gene polymorphism and increased risk of $\mathrm{CAD}$ under recessive $(\mathrm{OR}=3.39[1.77-6.50], P$ value $<0.001)$ and homozygote codominant $(\mathrm{OR}=3.96$ [2.44-6.45], $P$ value $<0.001)$ models. Conclusion. Our case-control study revealed a significant association between c.56C $>\mathrm{G}$ polymorphism and CAD in the Moroccan population. In addition, meta-analysis data supported the implication of this polymorphism in CAD susceptibility.
\end{abstract}

\section{Introduction}

Coronary artery disease (CAD) is the most common cardiovascular disease. It is caused by ischemia and hypoxia [1] due to the formation of plaque which hardens and narrows the coronary arteries, and it is the major cause of death worldwide, accounting for nearly 7 million deaths annually [2]. CAD is considered as the most common cause of death among both men and women over the age of 50 [3]. Environmental factors associated with CAD include obesity, alcohol intake, smoking, diabetes, hypertension, and dyslipidemia [4]. In addition, genetic factors contribute to the occurrence and development of CAD. Elevated triglyceride (TG) and low HDL-C levels are characteristic of dyslipidemia, which is associated with high risk of cardiovascular events $[4,5]$. The apolipoprotein A5 (apoAV) encoded by the APOA5 gene $[6,7]$ that belongs to the APOA1/C3/A4/ A5 gene cluster on chromosome 11q23 regulates lipoprotein lipase (LPL) activity $[8,9]$. New physiological roles of apoAV have been recently elucidated, such as control of 
chylomicron production in the intestine and TG accumulation in adipose tissue [10]. Epidemiological studies showed a strong correlation between increased TG concentrations and the elevation of coronary artery disease risk and more importantly with all-cause mortality [3, 11-14]. Moreover, the deficiency of the endogenous APOA5 gene leads to 4fold increased serum TG concentrations in mice and were decreased by $65 \%$ by overexpression of the human APOA 5 gene $[6,15]$. The role of APOA5 gene polymorphisms in $\mathrm{CAD}$ has been investigated in many studies and meta-analyses, the results are controversial [10, 16-19]. This discrepancy could be explained by the differences between ethnic populations that can contribute to the variation of prevalence rates of CAD. Furthermore, new studies are continuously being performed to identify whether APOA5 polymorphisms are associated with cardiovascular diseases occurrence [20-23]. In addition, accumulated data make it possible to conduct cumulative meta-analysis and assess the effects of APOA5 polymorphisms. To date, more than 13 polymorphic sites of APOA5 have been reported [24-26]. Indeed, several studies in different populations have found the association between the APOA5 polymorphisms and the risk of CAD [18, 20, 27]. The APOA5 gene polymorphism, c.56C $>\mathrm{G}$ variant located in the exon3, is of a special interest and has been reported to be associated with an increased risk of CAD in multiple ethnic populations probably through its association with hypertriglyceridemia [3, 12]. However, there are also discrepant reports of no association between this polymorphism and CAD risk [28, 29].

In order to evaluate the associations between APOA5 gene c.56C $>\mathrm{G}$ polymorphism and CAD, we performed a case-control study in a Moroccan population. In addition, we conducted a meta-analysis to confirm the contribution of this APOA5 polymorphism to CAD in various ethnic populations.

\section{Material and Methods}

2.1. Study Population. Study participants were recruited in the Medical Biology Center of Pasteur Institute of Morocco and Ibn Rochd Hospital. The present study involved 122 patients (73 men and 49 women, mean age 60.70 \pm 12.86 ) with coronary artery disease confirmed by coronary angiography, defined as the presence of at least one coronary artery with $\geq 50 \%$ organic stenosis. The study recruited also 134 unrelated non-CAD controls (42 men and 92 women, mean age $50.78 \pm 12.08$ ). All subjects were Moroccan adult volunteers and all provided their written informed consents. Participants completed a health and lifestyle questionnaire including sociodemographic characteristics, medical history, physical activity, medication intake, and alcohol and tobacco use. Clinical, biochemical, anthropometric parameters, and CAD risk factors (hypertension and diabetes mellitus) were assessed in both patients and controls. Hypertension was defined as systolic blood pressure $>140 \mathrm{mmHg}$ or/and diastolic blood pressure $>90 \mathrm{mmHg}$ or using antihypertensive drugs. Type 2 diabetes mellitus was diagnosed according to World Health Organization criteria. All women were nonpregnant and nonlactating. Healthy subjects had normal biochemical variables, were nonsmoking, and without history of CAD.

2.2. Biochemical Measurements. Blood samples were collected in EDTA tubes after at least 12 hours of overnight fast, centrifuged, and stored until subsequent laboratory analysis. Fasting plasma glucose, total cholesterol (TC), triglycerides (TG), and high-density lipoprotein cholesterol (HDL-C) levels were determined using the VITROS automate analyzer (5.1 FS Chemistry System). Low-density lipoprotein cholesterol (LDL-C) level was calculated according to the Friedewald formula.

Genomic DNA was isolated from peripheral leukocytes using the standard proteinase $K$ digestion followed by phenolchloroform extraction and ethanol precipitation. The c.56C $>\mathrm{G}$ polymorphism was genotyped by PCR-RFLP analysis. PCR reactions were performed in a Biometra thermal cycler, using Taq polymerase (Bioline), and restriction fragments were analyzed by agarose gel migration (3\%). Primers, PCR conditions, and RFLP analysis were performed according to a previously published protocol [30].

PCR of $157 \mathrm{bp}$ fragment of the $56 \mathrm{C}>\mathrm{G}$ polymorphism was performed using the following oligonucleotides: Forward: $5^{\prime}$ - GGC TCT TCT TTC AGG TGG GTCTCCG - $3^{\prime}$ and reverse: $5^{\prime}$ - GCC TTT CCG TGC CTG GGT GGT - $3^{\prime}$. The PCR started with an initial denaturing at $96^{\circ} \mathrm{C}$ for $5 \mathrm{~min}$, followed by 30 cycles of $96^{\circ} \mathrm{C}$ for $30 \mathrm{~s}, 64^{\circ} \mathrm{C}$ for $30 \mathrm{~s}$, and $72^{\circ} \mathrm{C}$ for $45 \mathrm{~s}$ and then a final extension of $72^{\circ} \mathrm{C}$ for $10 \mathrm{~min}$. The PCR products were digested for 2 hours at $65^{\circ} \mathrm{C}$ with TaqI restriction enzyme: the $56 \mathrm{C}$ allele presents a TaqI restriction site which is suppressed in the 56G allele [31]. All molecular analyses were performed in the Genomics and Human Genetic Laboratory at Pasteur Institute of Morocco.

2.3. Literature Search Strategy for the Meta-Analysis. We conducted a comprehensive literature search using PubMed. Articles published up to January 2020 were searched using the following key words: ("coronary heart disease" OR "coronary artery disease" OR "myocardial infarction") AND ("APOA5" OR "apolipoprotein A5" OR "C56G" OR "S19W" OR "rs3135506”) AND ("polymorphism” OR "SNP” OR “variant"). References cited in the identified articles were also analyzed to avoid missing any potential articles from the initial search. Data from studies were included in our metaanalysis only if the study met the following criteria: (1) only $\mathrm{CAD}$ as the outcome and the investigated variant should be c.56C > G exclusively or in the same study with other polymorphisms; (2) only the case-control studies were considered; (3) the genotype distribution of CAD cases and controls can be obtained from articles directly or by calculation; (4) the methods of data collection and analysis should be statistically acceptable; and (5) publications that presented data allowing such outcome to be derived were also included.

2.4. Statistical Analysis. Clinical and biochemical parameters normally distributed were expressed as mean$\mathrm{s} \pm$ standard deviation (SD), and nonnormally distributed 
data were expressed as median (Interquartile range) while qualitative parameters were expressed as frequencies. Student's $t$-test was applied for comparison of quantitative traits that follow a normal distribution. Otherwise, we used the Mann-Whitney test. The Hardy-Weinberg equilibrium (HWE) analysis of the genotyped SNP was performed using an exact test, available in the R package "compareGroups." The R package "SNPassoc" was used to examine the association between CAD and APOA5 genotypes. A $P$ value less than 0.05 was considered statistically significant.

Furthermore, Review Manager 5.3 (The Cochrane Collaboration) was used to elaborate meta-analysis results. Heterogeneity between studies was assessed using the chisquare-based Q-test, and the significance was fixed to $P<0.10$. The inconsistency index $I[2]$ was also calculated to evaluate the variation caused by the heterogeneity. The possible publication bias was estimated using funnel plot. The R software was used to calculate $P$ values of Egger's test.

\section{Results}

3.1. Subjects' Characteristics. Clinical characteristics and lipid parameters of patients with CAD and controls are presented in Table 1. As expected, triglycerides level (TG), glycemia (Gly), systolic blood pressure (SBP), and LDL-C were significantly higher among CAD patients than controls $(P$ values $<0.001)$. There were also significant differences in total cholesterol (TC) and diastolic blood pressure (DBP). No significant differences were found in body mass index (BMI) and HDL-C between both groups.

3.2. Association Analysis. We performed a case-controlbased association analysis of the c.56C $>\mathrm{G}$ polymorphism with CAD (Table 2). The genotype distribution of the studied variant was in HWE $(P$ value $>0.05)$. Logistic regression analysis adjusted for sex, age, BMI, and smoking showed a significant association between the c.56C $>\mathrm{G}$ polymorphism and CAD susceptibility under co-dominant, recessive, and log-additive models.

\subsection{Comparisons of Clinical and Biochemical Parameters} between APOA5 Genotypes. We compared biological and clinical traits between APOA5 genotypes under homozygote and heterozygote codominant, dominant, and recessive genetic models. The APOA5 c.56C > G polymorphism was significantly associated with increased levels of systolic and diastolic blood pressure, triglycerides, glycemia, and total cholesterol (Table 3).

3.4. Meta-Analysis. The literature search identified 109 potentially relevant articles, the publication date of these studies ranged from 2004 to 2018, forty-six of which were excluded after initial screening of title and abstract. The full text of remaining 67 studies was reviewed, and 56 additional articles were excluded because they did not meet the inclusion criteria. Finally, 11 studies were included in our meta-analysis in addition to our case-control study, with a
TABLE 1: Comparison of clinical and biochemical characteristics between controls and patients with CAD.

\begin{tabular}{lccc}
\hline & Controls $(n=134)$ & CAD $(n=122)$ & $P$ value \\
\hline Age (years) & $50.78 \pm 12.08$ & $60.70 \pm 12.86$ & $<0.001$ \\
Sbp (mmgHg) & $122[118-126]$ & $140[123-160]$ & $<0.001$ \\
Dbp (mmgHg) & $77.49 \pm 7.97$ & $80.83 \pm 12.99$ & 0.015 \\
BMI (kg/m $\left.{ }^{2}\right)$ & $26.49 \pm 4.11$ & $25.68 \pm 4.73$ & 0.148 \\
TG $(\mathrm{mg} / \mathrm{dl})$ & $97[71.25-122.5]$ & $156[105.5-179.2]$ & $<0.001$ \\
LDL-C (mg/dl) & $115 \pm 28$ & $141 \pm 46$ & $<0.001$ \\
HDL-C (mg/dl) & $51 \pm 13$ & $50 \pm 18$ & 0.660 \\
Gly (mg/dl) & $89[85-99]$ & $119[94-153]$ & $<0.001$ \\
TC (mg/dl) & $188 \pm 28$ & $205 \pm 53$ & 0.002 \\
Diabetes $(\%)$ & $0(0 \%)$ & $38(31 \%)$ & $<0.001$ \\
Smoking $(\%)$ & $0(0 \%)$ & $21(31 \%)$ & $<0.001$ \\
\hline
\end{tabular}

Sbp: systolic blood pressure, Dbp diastolic blood pressure, BMI: body mass index, TG: Triglycerides, LDL: low-density lipoprotein cholesterol, HDL: high-density lipoprotein cholesterol, Gly: glycemia, TC: serum total cholesterol. Data are expressed as mean \pm standard deviation or median (interquartile range) for quantitative parameters and as frequencies for qualitative parameters.

total of 5705 CAD patients and 7242 controls. A flow chart of study selection is shown in Figure 1 and characteristics of included are presented in Table 4.

Meta-analysis of the 12 genetic association studies and publication bias analyses are summarized in Table 5. The c.56C $>\mathrm{G}$ polymorphism was significantly associated with genetic predisposition to $\mathrm{CAD}$ under recessive mode of inheritance $(\mathrm{OR}=3.39 ; 95 \% \mathrm{CI}=[1.77-6.50] ; \quad P$ value $<0.001)$. Moreover, using the homozygote codominant model, the GG genotype was significantly associated with susceptibility to $\mathrm{CAD}$ compared to the $\mathrm{CC}$ genotype $(\mathrm{OR}=3.96 ; 95 \% \mathrm{CI}=[2.44-6.45] ; P$ value $<0.001)$. A random-effect model was used to estimate pooled odds ratios if considerable heterogeneity was detected (Q-statistic: $P<0.10$ or $\left.I^{2}>50 \%\right)$. Otherwise, a fixed-effect model was used (Q-statistic: $P>0.10$ and $I^{2}<50 \%$ ). No significant publication bias was shown using both funnel plot analyses and Egger's test in all tested genetic models.

\section{Discussion}

Coronary artery disease (CAD) is a multifactorial disease in which atherosclerotic plaque accumulates inside the coronary arteries resulting in myocardial infarction and mortality. Hypertriglyceridemia is significantly associated with the increased risk of CAD, as elevated levels of triglycerides (TG) may lead to plaque formation [39-41]. The APOA5/4/ C3/A1 gene cluster on chromosome 11q23 plays an important role in TG regulation; particularly variants occurring in the APOA5 gene have been extensively analyzed for their relationship with TG metabolism and cardiovascular diseases susceptibility $[34,36,42]$. Therefore, the present study was designed to examine the implication of the c.56C $>\mathrm{G}$ APOA 5 variant as a coronary artery disease risk factor in the Moroccan population.

Logistic regression analysis adjusted for possibly confounding factors (sex, age, BMI, and smoking) showed a significant association between c.56C $>$ G APOA5 variant 
TABLE 2: Genotypic distribution of the 56C > G variant in patients with coronary artery disease and control subjects.

\begin{tabular}{|c|c|c|c|c|c|c|c|c|c|c|}
\hline \multirow{2}{*}{$\begin{array}{l}\text { Genetic } \\
\text { model }\end{array}$} & \multirow{2}{*}{$\begin{array}{c}\text { Controls } \\
n(\%)\end{array}$} & \multirow{2}{*}{$\begin{array}{c}\text { Cases } n \\
(\%)\end{array}$} & \multicolumn{2}{|c|}{ Codominant } & \multicolumn{2}{|c|}{ Dominant } & \multicolumn{2}{|c|}{ Recessive } & \multicolumn{2}{|c|}{ Log-additive } \\
\hline & & & $\begin{array}{c}\text { OR } \\
(95 \% \mathrm{CI})\end{array}$ & $P$ value & $\begin{array}{c}\text { OR } \\
(95 \% \mathrm{CI})\end{array}$ & $P$ value & $\begin{array}{c}\text { OR } \\
(95 \% \mathrm{CI})\end{array}$ & $P$ value & $\begin{array}{c}\text { OR } \\
(95 \% \mathrm{CI})\end{array}$ & $P$ value \\
\hline $\mathrm{C} / \mathrm{C}$ & $117(87.3)$ & $93(76.2)$ & 1.00 & 0.001 & $\begin{array}{c}1.90 \\
(0.87-4.15)\end{array}$ & 0.107 & $\begin{array}{c}13.14 \\
(2.56-67.47)\end{array}$ & $<0.001$ & $\begin{array}{c}2.10 \\
(1.19-3.69)\end{array}$ & 0.008 \\
\hline $\mathrm{C} / \mathrm{G}$ & $15(11.2)$ & $13(10.7)$ & $0.80[0.30-2.11]$ & & & & & & & \\
\hline $\mathrm{G} / \mathrm{G}$ & $2(1.5)$ & $16(13.1)$ & $\begin{array}{c}12.85 \\
{[2.49-66.22]}\end{array}$ & & & & & & & \\
\hline $\begin{array}{l}\text { MAF } \\
\text { HWE } P \\
\text { value }\end{array}$ & $\begin{array}{l}0.071 \\
0.125\end{array}$ & $\begin{array}{r}0.184 \\
<0.001\end{array}$ & & & & & & & & \\
\hline
\end{tabular}

MAF: minor allele frequency, HWE: $P$ value for Hardy-Weinberg equilibrium.

TABLE 3: Association between APOA5 variant genotypes and clinical and biochemical parameters.

\begin{tabular}{|c|c|c|c|c|c|c|c|}
\hline \multirow{2}{*}{ Parameter } & \multicolumn{3}{|c|}{ Genotypes } & \multirow{2}{*}{$\begin{array}{c}P \text { value } \\
(\mathrm{CC} \text { vs. } \mathrm{CG})\end{array}$} & \multirow{2}{*}{ 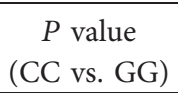 } & \multirow{2}{*}{$\begin{array}{c}P \text { value } \\
(\mathrm{CC} \text { vs. } \mathrm{CG}+\mathrm{GG})\end{array}$} & \multirow{2}{*}{$\begin{array}{c}P \text { value } \\
(\mathrm{CC}+\mathrm{CG} \text { vs. } \mathrm{GG})\end{array}$} \\
\hline & $\mathrm{CC}$ & CG & GG & & & & \\
\hline & $(n=210)$ & $(n=28)$ & $(n=18)$ & & & & \\
\hline Dbp (mmgHg) & $78.57 \pm 9.78$ & $79.18 \pm 16.79$ & $84.94 \pm 8.73$ & 0.779 & 0.008 & 0.102 & 0.016 \\
\hline Sbp (mmgHg) & 123 [119-133] & 127 [120-146] & 147 [135-175] & 0.285 & $<0.001$ & 0.005 & $<0.001$ \\
\hline BMI $\left(\mathrm{kg} / \mathrm{m}^{2}\right)$ & $26.18 \pm 4.22$ & $25.66 \pm 4.99$ & $25.93 \pm 5.84$ & 0.550 & 0.821 & 0.568 & 0.866 \\
\hline $\mathrm{LDL}(\mathrm{mg} / \mathrm{dl})$ & $126 \pm 39$ & $121 \pm 35$ & $150 \pm 50$ & 0.531 & 0.064 & 0.327 & 0.057 \\
\hline $\mathrm{HDL}(\mathrm{mg} / \mathrm{dl})$ & $51 \pm 16$ & $50 \pm 13$ & $45 \pm 16$ & 0.667 & 0.131 & 0.218 & 0.132 \\
\hline $\mathrm{TC}(\mathrm{mg} / \mathrm{dl})$ & $194 \pm 40$ & $192 \pm 37$ & $230 \pm 64$ & 0.816 & 0.033 & 0.125 & 0.032 \\
\hline $\mathrm{TG}(\mathrm{mg} / \mathrm{dl})$ & $113[75-151]$ & $105[76-133]$ & $212[158-273]$ & 0.477 & $<0.001$ & 0.021 & $<0.001$ \\
\hline Gly (mg/dl) & 98 [88-119] & 92 [90-95] & 115 [99-181] & 0.281 & 0.018 & 0.557 & 0.012 \\
\hline
\end{tabular}

Sbp: systolic blood pressure, Dbp: diastolic blood pressure, BMI: body mass index, TG: triglycerides, LDL: low-density lipoprotein cholesterol, HDL: highdensity lipoprotein cholesterol, Gly: glycemia, TC: serum total cholesterol.

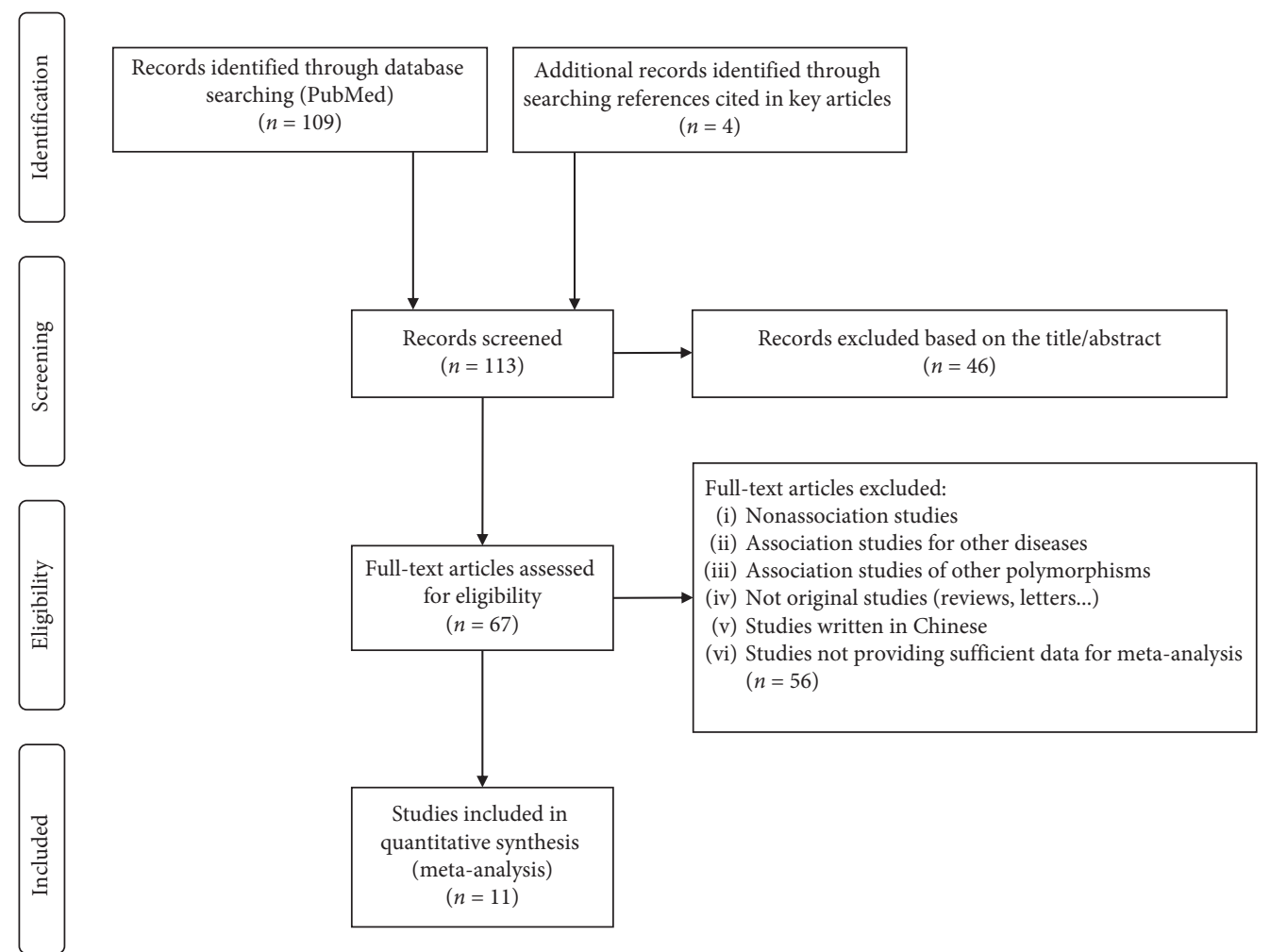

FIgURE 1: Flow chart of the study selection process for eligible studies. 


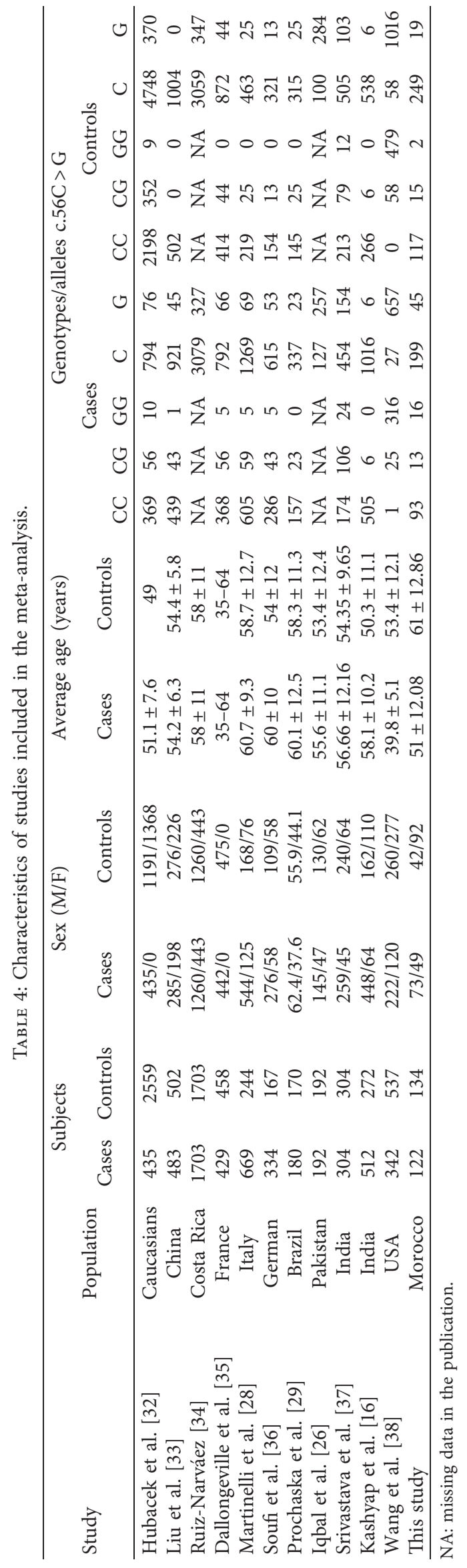


TABle 5: Association between c.56C $>\mathrm{G}$ variant and risk of CAD in the meta-analysis.

\begin{tabular}{|c|c|c|c|c|c|c|c|c|}
\hline \multirow{2}{*}{ Model } & \multirow{2}{*}{$\begin{array}{c}\text { Number of } \\
\text { included studies* }\end{array}$} & \multicolumn{3}{|c|}{ Test of association } & \multicolumn{3}{|c|}{ Test of heterogeneity } & \multirow{2}{*}{$\begin{array}{c}\text { Publication bias } \\
P \text { value (Egger's test) }\end{array}$} \\
\hline & & OR & $95 \% \mathrm{CI}$ & $P$ value & Model & $P$ value & $I^{2}(\%)$ & \\
\hline $\begin{array}{l}\text { Recessive model } \\
(\mathrm{CC}+\text { CG vs. GG) }\end{array}$ & 10 & 3.39 & {$[1.77-6.50]$} & $<0.001$ & Random & 0.05 & 50 & 0.086 \\
\hline $\begin{array}{l}\text { Dominant model } \\
\text { (CC vs. } C G+G G)\end{array}$ & 10 & 1.35 & {$[0.97-1.87]$} & 0.07 & Random & 0.001 & 67 & 0.700 \\
\hline $\begin{array}{l}\text { Co-dominant model } \\
\text { (CC vs. CG) }\end{array}$ & 10 & 1.17 & [0.84-1.63] & 0.35 & Random & 0.002 & 65 & 0.798 \\
\hline $\begin{array}{l}\text { Co-dominant model } \\
\text { (CC vs. GG) }\end{array}$ & 10 & 3.96 & [2.44-6.45] & $<0.001$ & Fixed & 0.31 & 15 & 0.914 \\
\hline $\begin{array}{l}\text { Allele contrast } \\
(\mathrm{C} \text { vs. } \mathrm{G})\end{array}$ & 12 & 1.29 & [1-1.68] & 0.05 & Random & $<0.001$ & 80 & 0.117 \\
\hline
\end{tabular}

* Number of included studies includes our case control study data.

and coronary artery disease. Various studies were performed in different populations in order to assess the association between this variant and CAD, but the results are conflicting. Consistent with our findings, the c.56C > G SNP was significantly associated with increased risk of CAD in a previous study on Chinese patients [33]. Similarly, a significant susceptibility to CAD was detected in subjects from Czech Republic carrying the rare allele of the c.56C > G SNP [32]. In contrast, two studies including patients of Italian and French origins failed to detect a relationship between c.56C > G SNP risk allele and CAD [28, 35].

Currently, the biological mechanisms by which the c.56C > G (S19W) missense polymorphism regulates the plasma triglyceride levels are not sufficiently well elucidated and need further research. Talmud et al. suggested that the c.56C $>\mathrm{G}$ variant may have functional effects on the APOA5 protein [30]. The substitution of hydrophilic serine to hydrophobic tryptophan residue could affect APOA5 signal peptide activity with the endoplasmic reticulum, suggesting that this amino acid change is potentially functional and may reduce the amount of functioning protein [30]. Transgenic and gene knockout mice showed an inverse regulation between APOA5 expression and plasma TG levels, supporting a role for the apolipoprotein A5 in human triglycerides secretion [6].

In the present study, the c.56C $>\mathrm{G}$ variant showed significant association with plasma triglyceride levels. We observed elevated triglyceride levels in subjects carrying the GG genotype compared to noncarriers. Similarly, TG levels were also significantly higher in Turkish subjects carrying the GG genotype [43]. The rare allele of the c.56C > G polymorphism was significantly associated with increased TG levels in previous studies on subjects from Spain [44], United Kingdom [30], and Brazil [3].

In contrast, we did not find any relationship between HDL-C levels in subjects carrying the G allele compared to noncarriers, which is consistent with findings reported by other studies $[29,33,36]$. A recent study showed that elevated levels of fasting TG are significantly associated with increased risk of myocardial infarction and gradually decreased levels of HDL-C [45]. Despite this negative correlation that have been shown between HDL-C and plasma TG in several studies, there was no evidence of any association between decreased HDL-C levels and the APOA5 G allele [35].

The association between the c.56C $>\mathrm{G}$ polymorphism and susceptibility to CAD remains controversial. To elucidate this discrepancy, we performed a meta-analysis considering the data from all studies exploring the association between this APAO5 variant and increased risk of CAD in various ethnicities.

Several studies were interested in gathering data on APOA5 polymorphisms implication in CAD susceptibility [18, 46-50]. Our meta-analysis showed a strong association between the c.56C $>\mathrm{G}$ polymorphism and the risk of $\mathrm{CAD}$ under the recessive and homozygote codominant genetic models. Similarly, a previous meta-analysis based on 5 association studies reported a strong association of the c.56C $>$ G polymorphism and genetic predisposition to CAD under the recessive genetic model [46]. In contrast, Zhou and colleagues performed a meta-analysis including 7 studies, and they did not find any significant implication of the c.56C > G variant in CAD susceptibility [19].

Our work may have some limitations. Firstly, CAD is a multifactorial and polygenic disorder involving complex genes and environmental interactions that were not evaluated. Secondly, articles in other languages than English were not included in this meta-analysis. That may result in a bias, although funnel plots and Egger's test showed no significant bias. Lastly, we performed a comprehensive literature research to collect all eligible studies; however, the number of included studies was not large. Thus, further genetic association studies are needed to evaluate the relationship between this APOA5 variant and CAD risk in different populations.

\section{Conclusion}

In summary, the current case-control study showed that the $56 \mathrm{C}>\mathrm{G}$ polymorphism is a CAD risk factor in the Moroccan population. In addition, our results clarify that the overall conclusion of the literature to data indicates a significant association between $56 \mathrm{C}>\mathrm{G}$ polymorphism and $\mathrm{CAD}$ in different populations, supporting our case-control study results. An improved case-control investigation with larger sample sizes and a balanced gender structure could provide 
sufficient statistical power to obtain a clear conclusion on the contribution of the 56C $>$ G APOA5 polymorphism in CAD susceptibility.

\section{Data Availability}

All data used in this study are included within the article, and a supplementary information file of meta-analysis plots is attached.

\section{Conflicts of Interest}

The authors declare no conflicts of interest.

\section{Acknowledgments}

This work was supported by the European Commission FP7 Integrated Project MEDIGENE (FP7-279171-1) and Pasteur Institute of Morocco (IPM).

\section{Supplementary Materials}

The funnel plots of the meta-analysis showing the association of the C56G polymorphism with CAD under all studied inheritance models(recessive, dominant, homozygote codominant, heterozygote co-dominant and allelic models). (Supplementary Materials)

\section{References}

[1] Q. Chen, S. E. Reis, C. Kammerer et al., "Association of antioxidized LDL and candidate genes with severity of coronary stenosis in the women's ischemia syndrome evaluation study," Journal of Lipid Research, vol. 52, no. 4, pp. 801-807, 2011.

[2] S. Chen, X. Xie, Y. Wang et al., "Association between leukocyte mitochondrial DNA content and risk of coronary heart disease: a case-control study," Atherosclerosis, vol. 237, no. 1, pp. 220-226, 2014.

[3] F. M. De Andrade, S. W. Maluf, J. B. Schuch et al., "The influence of the S19W SNP of the APOA5 gene on triglyceride levels in southern Brazil: interactions with the APOE gene, sex and menopause status," Nutrition, Metabolism and Cardiovascular Diseases, vol. 21, no. 8, pp. 584-590, 2011.

[4] D. M. Waterworth, S. L. Ricketts, K. Song et al., "Genetic variants influencing circulating lipid levels and risk of coronary artery disease," Arteriosclerosis, Thrombosis, and Vascular Biology, vol. 30, no. 11, pp. 2264-2276, 2010.

[5] A. Brautbar, D. Covarrubias, J. Belmont et al., "Variants in the APOA5 gene region and the response to combination therapy with statins and fenofibric acid in a randomized clinical trial of individuals with mixed dyslipidemia," Atherosclerosis, vol. 219, no. 2, pp. 737-742, 2011.

[6] L. A. Pennacchio, M. Olivier, J. A. Hubacek et al., "An apolipoprotein influencing triglycerides in humans and mice revealed by comparative sequencing," Science, vol. 294, no. 5540, pp. 169-173, 2001.

[7] H. N. van der Vliet, M. G. Sammels, A. C. J. Leegwater et al., "Apolipoprotein A-V," Journal of Biological Chemistry, vol. 276, no. 48, pp. 44512-44520, 2001.

[8] S. K. Nilsson, J. Heeren, G. Olivecrona, and M. Merkel, "Apolipoprotein A-V; a potent triglyceride reducer," Atherosclerosis, vol. 219, no. 1, pp. 15-21, 2011.
[9] J. A. Beckstead, M. N. Oda, D. D. O. Martin et al., "Structure-function studies of human apolipoprotein A-V: a regulator of plasma lipid homeostasis $\dagger$," Biochemistry, vol. 42, no. 31, pp. 9416-9423, 2003.

[10] M. Guardiola and J. Ribalta, "Efficiency meets accountability: Performance implications of supply chain configuration, control, and capabilities*," Current Atherosclerosis Reports, vol. 19, no. 7, p. 30, 2017.

[11] J. Liu, F.-F. Zeng, Z.-M. Liu, C.-X. Zhang, W.-h. Ling, and Y.-M. Chen, "Effects of blood triglycerides on cardiovascular and all-cause mortality: a systematic review and meta-analysis of 61 prospective studies," Lipids in Health and Disease, vol. 12, no. 1, p. 159, 2013.

[12] S. Li, B. Hu, Y. Wang, D. Wu, L. Jin, and X. Wang, "Influences of APOA5 variants on plasma triglyceride levels in Uyghur population," PloS One, vol. 9, no. 10, Article ID e110258, 2014.

[13] H. Pikhart, J. A. Hubáček, A. Peasey, R. Kubínová, and M. Bobák, "Association between fasting plasma triglycerides, all-cause and cardiovascular mortality in Czech population. Results from the HAPIEE study," Computers \& Industrial Engineering, vol. 64, no. 3, pp. S355-S361, 2015.

[14] L. E. Eberly, J. Stamler, and J. D. Neaton, "Relation of triglyceride levels, fasting and nonfasting, to fatal and nonfatal coronary heart disease," Archives of Internal Medicine, vol. 163, no. 9, pp. 1077-1083, 2003.

[15] H. N. van der Vliet, F. G. Schaap, J. H. M. Levels et al., "Adenoviral overexpression of apolipoprotein A-V reduces serum levels of triglycerides and cholesterol in mice," Computers \& Industrial Engineering, vol. 295, no. 5, pp. 1156-1159, 2002.

[16] S. Kashyap, S. Kumar, V. Agarwal, D. P. Misra, M. K. Rai, and A. Kapoor, "The association of polymorphic variants, rs2267788, rs1333049 and rs2383207 with coronary artery disease, its severity and presentation in North Indian population," Gene, vol. 648, pp. 89-96, 2018.

[17] H. Hassani Idrissi, W. Hmimech, B. Diakite et al., "Association of G894T eNOS, 4G/5G PAI and T1131C APOA5 polymorphisms with susceptibility to myocardial infarction in Morocco," Meta Gene, vol. 9, pp. 56-61, 2016.

[18] H. Ye, A. Zhou, Q. Hong et al., "Positive association between APOA5 rs662799 polymorphism and coronary heart disease: a case-control study and meta-analysis," PLoS One, vol. 10, no. 8, Article ID e0135683, 2015.

[19] J. Zhou, L. Xu, R. S. Huang et al., “Apolipoprotein A5 gene variants and the risk of coronary heart disease: a case-control study and meta-analysis," Molecular Medicine Reports, vol. 8, no. 4, pp. 1175-1182, 2013.

[20] Y. Sun, R. B. Zhou, and D. M. Chen, "APOA5 -1131T >C and APOC3 -455T $>$ C polymorphisms are associated with an increased risk of coronary heart disease," Computers \& Industrial Engineering, vol. 14, no. 4, pp. 18218-18228, 2015.

[21] Y. Wang, Z. Lu, J. Zhang et al., "The APOA5 rs662799 polymorphism is associated with dyslipidemia and the severity of coronary heart disease in Chinese women," Lipids in Health and Disease, vol. 15, no. 1, 2016.

[22] I. San Mauro Martín, J. Blumenfeld Olivares, E. Pérez Arruche et al., "Genomic influence in the prevention of cardiovascular diseases with a sterol-based treatment," Diseases, vol. 6, no. 2, p. 24, 2018.

[23] M. Vrablik, J. A. Hubacek, D. Dlouha, M. Satny, V. Adamkova, and R. Ceska, "Strong association between APOA5 gene polymorphisms and hypertriglyceridaemic episodes," Folia Biologica, vol. 65, no. 65, pp. 188-194, 2019. 
[24] G. Ken-Dror, U. Goldbourt, and R. Dankner, "Different effects of apolipoprotein A5 SNPs and haplotypes on triglyceride concentration in three ethnic origins," Journal of Human Genetics, vol. 55, no. 5, pp. 300-307, 2010.

[25] B. Can Demirdöğen, E. Şahin, A. Türkanoğlu Özçelik, S. Bek, Ş Demirkaya, and O. Adali, "Apolipoprotein A5 polymorphisms in Turkish population: association with serum lipid profile and risk of ischemic stroke," Molecular Biology Reports, vol. 39, no. 12, pp. 10459-10468, 2012.

[26] R. Iqbal, N. Jahan, Y. Sun, and H. Xue, "Genetic association of lipid metabolism related SNPs with myocardial infarction in the Pakistani population," Molecular Biology Reports, vol. 41, no. 3, pp. 1545-1552, 2014.

[27] Y. You, Y.-H. Wu, Y. Zhang et al., "Effects of polymorphisms in APOA5 on the plasma levels of triglycerides and risk of coronary heart disease in Jilin, northeast China: a case-control study," BMJ Open, vol. 8, no. 6, Article ID e020016, 2018.

[28] N. Martinelli, E. Trabetti, A. Bassi et al., "The $-1131 \mathrm{~T}>\mathrm{C}$ and S19W APOA5 gene polymorphisms are associated with high levels of triglycerides and apolipoprotein C-III, but not with coronary artery disease: an angiographic study," Atherosclerosis, vol. 191, no. 2, pp. 409-417, 2007.

[29] C. L. Prochaska, G. Picheth, M. I. Anghebem-Oliveira et al., "The polymorphisms $-1131 \mathrm{~T}>\mathrm{C}$ and the S19W of the APOA5 gene are not associated with coronary artery disease in a Brazilian population," Clinical Chemistry and Laboratory Medicine, vol. 48, no. 3, pp. 419-422, 2010.

[30] P. J. Talmud, E. Hawe, S. Martin et al., "Relative contribution of variation within the APOC3/A4/A5 gene cluster in determining plasma triglycerides," Human Molecular Genetics, vol. 11, no. 24, pp. 3039-3046, 2002.

[31] F. Francés, D. Corella, J. V. Güllü, M. Guillén, J. I. González, and O. Portolés, "Validating a rapid method for detecting common polymorphisms in the APOA5 gene by melting curve analysis using LightTyper," Clinical Chemistry, vol. 51, no. 7, pp. 1279-1282, 2005.

[32] J. Hubacek, Z. Škodová, V. Adámková, V. Lánská, and R. Poledne, "The influence of APOAV polymorphisms (T$1131>\mathrm{C}$ and $\mathrm{S} 19>\mathrm{W}$ ) on plasma triglyceride levels and risk of myocardial infarction," Clinical Genetics, vol. 65, no. 2, pp. 126-130, 2004.

[33] H. Liu, S. Zhang, J. Lin et al., "Association between DNA variant sites in the apolipoprotein $\mathrm{A} 5$ gene and coronary heart disease in Chinese," Metabolism, vol. 54, no. 5, pp. 568-572, 2005.

[34] E. A. Ruiz-Narváez, Y. Yang, Y. Nakanishi, J. Kirchdorfer, and H. Campos, "APOC3/A5 haplotypes, lipid levels, and risk of myocardial infarction in the Central Valley of Costa Rica," Journal of Lipid Research, vol. 46, no. 12, pp. 2605-2613, 2005.

[35] J. Dallongeville, D. Cottel, M. Montaye, V. Codron, P. Amouyel, and N. Helbecque, "Impact of APOA5/A4/C3 genetic polymorphisms on lipid variables and cardiovascular disease risk in French men," International Journal of Cardiology, vol. 106, no. 2, pp. 152-156, 2006.

[36] W. Soufi, A. M. Sattler, B. Kurt, and J. R. Schaefer, "Mutation screening of the APOA5 gene in subjects with coronary artery disease," Journal of Investigative Medicine, vol. 60, no. 7, pp. 1015-1019, 2012.

[37] R. Srivastava, P. Singh, P. Verma et al., "Influence of APOA5 (rs662799 and rs3135506) gene polymorphism in acute myocardial infarction patients and its association with basic coronary artery disease risk factors," Journal of Applied Pharmaceutical Science, vol. 5, no. 6, pp. 8-14, 2015.
[38] F. Wang, I. Z. Wang, S. Ellis et al., "Analysis of causal effect of APOA5 variants on premature coronary artery disease," Annals of Human Genetics, vol. 82, no. 6, pp. 437-447, 2018.

[39] K. Geurian, J. B. Pinson, and C. W. Weart, "The triglyceride connection in atherosclerosis," Annals of Pharmacotherapy, vol. 26, no. 9, pp. 1109-1117, 1992.

[40] N. Zaman, M. Habeel Dar, Y. Adnan, L. Noor, G. Naz, and Zahoor, "Nonfasting apo-lipoprotein B \& triglyceride levels as a predictor of coronary heart disease in type II diabetic patients," Pakistan Journal of Medical Sciences, vol. 34, no. 2, pp. 247-252, 2018.

[41] Y. Ling, J. Jiang, B. Wu, and X. Gao, "Serum triglyceride, highdensity lipoprotein cholesterol, apolipoprotein B, and coronary heart disease in a Chinese population undergoing coronary angiography," Journal of Clinical Lipidology, vol. 11, no. 3, pp. 646-656, 2017.

[42] R. Elosua, J. M. Ordovas, L. A. Cupples et al., "Variants at theAPOA5locus, association with carotid atherosclerosis, and modification by obesity: the Framingham Study," Journal of Lipid Research, vol. 47, no. 5, pp. 990-996, 2006.

[43] U. Hodoglugil, S. Tanyolaç, D. W. Williamson, Y. Huang, R. W. Mahley, and A.-V. Apolipoprotein, "A potential modulator of plasma triglyceride levels in Turks," Journal of Lipid Research, vol. 47, no. 1, pp. 144-153, 2006.

[44] M.-J. Ariza, M.-Á. Sánchez-Chaparro, F.-J. Barón et al., "Firms' green R\&D cooperation behaviour in a supply chain: Technological spillover, power and coordination," BMC Medical Genetics, vol. 11, no. 1, p. 66, 2010.

[45] Z.-Y. Jiao, X.-T. Li, Y.-B. Li et al., "Correlation of triglycerides with myocardial infarction and analysis of risk factors for myocardial infarction in patients with elevated triglyceride," Journal of Thoracic Disease, vol. 10, no. 5, pp. 2551-2557, 2018.

[46] Z. Zhang, B. Peng, R. Gong et al., "Apolipoprotein A5 polymorphisms and risk of coronary artery disease: a metaanalysis," BioScience Trends, vol. 5, no. 4, pp. 165-172, 2011.

[47] Y.-y. Li, X.-y. Wu, J. Xu, Y. Qian, C.-w. Zhou, and B. Wang, "Apo A5 -1131T/C, FgB -455G/A, -148C/T, and CETP TaqIB gene polymorphisms and coronary artery disease in the Chinese population: a meta-analysis of 15,055 subjects," Molecular Biology Reports, vol. 40, no. 2, pp. 1997-2014, 2013.

[48] G. Zhai, M. Li, and C. Zhu, "APOA5 -1131T/C polymorphism is associated with coronary artery disease in a Chinese population: a meta-analysis," Clinical Chemistry and Laboratory Medicine, vol. 49, no. 49, pp. 535-539, 2011.

[49] J. Zhang, D. G. Wan, H. L. Song, and W. G. Zhang, "Review APOA5 -1131T/C polymorphism and coronary artery disease susceptibility in Chinese population: an updated meta-analysis," Genetics and Molecular Research, vol. 14, no. 4, pp. 12330-12339, 2015.

[50] C. T. Johansen, S. Kathiresan, and R. A. Hegele, "Genetic determinants of plasma triglycerides," Journal of Lipid Research, vol. 52, no. 2, pp. 189-206, 2011. 